by scientific investigators in general or by those actually engaged in technical problems which involve, either partly or wholly, considerations of a definitely colloid nature.

The reports of the British Association Committee on Colloids have dealt with a number of the subjects referred to above, and also in some detail with a number of industrial operations involving colloid chemistry. Several scientific subjects and technical applications have not as yet been included. It is hoped that a number of these will form the subjectmatter of the fourth report:

\title{
A New Problem of Coastal Navigation.
}

I $\mathrm{N}$ coastal navigation there is no problem of greater general utility than that of fixing positions by means of "cross-bearings" of two terrestrial objects. If, for instance, we have one object bearing due north and a second bearing due east, we have but to lay down the bearings reversed, south from the one and west from the other, and the point of intersection of the two lines of bearing fixes the position of the ship.

When, as is often the case, only one light is available, it has generally been assumed that no more information could be obtained from its observed bearing than a single line of bearing, somewhere upon which the ship's position must lie. But a little work recently published in Australia by Capt. H. H. Edmonds, of the British Mercantile Marine, introduces us to a comparatively novel use for a single light, for he shows how by three bearings, with the intervals between the bearings noted, we may deduce that most valuable piece of information, the actual course under the influence of wind and current which is being made good "over the ground."

The problem is not wholly new, for in its most general form questions to be solved by protraction have been proposed in recent years in the Board of Trade examinations for masters and mates, but in much too complicated a form to be of service in actual work at sea. The advance effected by Capt. Edmonds lies in the application of a simple form of table, reference to which gives the course made good in a moment with no more trouble than the division of one quantity by another.

In the construction of the table it is assumed that the intervals in azimuth are equal, the times of the three observations being carefully noted. One of these being divided by the other, a "ratio" is obtained which serves as an argument of the table.

The use of the table will easily appear from one of the examples given: "A light bore N.W.; after a time-interval of 39 minutes it bore W.N.W.; after another time-interval of $2 \mathrm{I}$ minutes it bore W."

A portion of the table to be employed is given below :

$\begin{array}{cc}\begin{array}{c}\text { Bearing interval } 22^{\circ} 30^{\prime} \text {. } \\ \text { Rourse angle. }\end{array} & \begin{array}{cc}\text { Ratio. } \\ 31^{\circ}\end{array} \\ 32^{\circ} & 1884 \\ 33^{\circ} & \mathrm{I} \cdot 839 \\ \mathrm{I} & \mathrm{I} \cdot 796\end{array}$

The solution is given as follows: "Dividing the greater time-interval by the lesser, we obtain a ratio I. 857 ; with this ratio, under bearing $22 \frac{1}{2}^{\circ}$, we obtain the course-angle $32^{\circ}$, which, allowed forward of the first bearing, gives course made good N. I $3^{\circ} \mathrm{W} . "$

The table of the text-book, as has been shown, proceeds upon the assumption that the intervals in azimuth should be equal. A still more advantageous form of table, it would seem, could be obtained by taking the observations at equal intervals of time, with differences of bearing in general unequal. This form of table presents at least two very attractive

1 "'Course Angle Tables for Finding a Course Made Good.' By H. H. Edmonds. (Sydney: Turner and Henderson.)

No. 2669 , VOL. IO6] features: first, that we have no ratio to calculate, and, secondly, that it is much simpler in practice to observe a bearing at a given time by watch than to wait, watch in hand, at the compass until a given bearing comes on. For air navigation in particular such a table should be invaluable, since it is quite unnecessary to fix the identity of the particular point observed, and, indeed, the problem has already engaged the attention of some of the able men who have taken up the problems connected with the navigation of the air. In a recently published work by Lieut. Dumbleton $^{2}$ the following passage occurs, taken apparently from a lecture by Squadron-Leader Wimperis before the Royal Aeronautical Society: "How is one, then, to determine the course being made good? Perhaps the best method is to take times and bearings of the object as it passes through the points $E, F$, and $G$, such that the time from $E$ to $F$ is equal to the time from $F$ to G."

The lecturer goes on to describe a method of solving the problem by protraction, suitable, perhaps, for an airship, but scarcely practicable probably for a heavierthan-air machine.

The following extract shows the form which such a table, devised for equal differences of time, would assume:

\section{Angle of Inclination to First Line of Bearing.}

Difference

between first Difference between second and third bearings.

and second

bearings.

$38^{\circ} \quad 5^{\circ}$

$\begin{array}{llll}38^{\circ} & \cdots & 35^{\circ}\end{array}$

$\begin{array}{llll}36^{\circ} & \ldots & 34.7^{\circ}\end{array}$

$34^{\circ} \ldots 34^{\circ} 0^{\circ}$

$\begin{array}{llll}3^{\circ} & \cdots & 33.2^{\circ}\end{array}$

o.74

$54^{\circ}$
$36.5^{\circ}$

F.

$52^{\circ}$

0.71

0.68

$36.0^{\circ}$

0.76
0.73

$38 \cdot 0^{\circ}$
$37 \cdot 4^{\circ}$

0.78

$30^{\circ} \quad \ldots \quad 3^{2 \cdot I^{\circ}}$

$0.64 \quad 34.4^{\circ}$

0.69

$36.7^{\circ}$

$36.7^{\circ} \quad 0.71$

$35.7^{\circ} \quad 0.67$

$\begin{array}{llll}33.3^{\circ} & 0.62 & 34.6^{\circ} & 0.64\end{array}$

The column marked $F$ requires, perhaps, some explanation. The primary object of the table is to give the course made good. But when at first bearing the distance from light is known with reasonable accuracy, the distance in final position is obtained by multiplying first distance by factor $F$. The following example will serve to illustrate the use of the table:

From a ship steaming N. $25^{\circ} \mathrm{W}$. 16 knots, the Smalls Light (lat. $5^{\mathrm{I}^{\circ}} 44^{\prime} \mathrm{N}$., long. $5^{\circ} 40^{\prime} \mathrm{W}$.) bore N. $26^{\circ}$ E. Twenty minutes later the Light bore N. $59^{\circ}$ E., and again after a further twenty minutes S. $67^{\circ} \mathrm{E}$. Find true course made good.

For first difference of bearing we have $59^{\circ}-26^{\circ}=33^{\circ}$, and for second $113^{\circ}-59^{\circ}=54^{\circ}$.

Entering table with $33^{\circ}$ on left and $54^{\circ}$ at top of the page, we have the angle $35^{\circ}$ nearly.

This angle applied to the first bearing, N. $26^{\circ} \mathrm{E}$., gives N. $9^{\circ} \mathrm{W}$. as true course made good over the ground.

To illustrate the use of the factor $F$, let us suppose that by means of the line of position from a star observation or otherwise, distance at first bearing was found to be ro miles. Then final distance $=10 \times \mathrm{F}=$ Io $\times 0.68=6.8$ miles.

2 "Principles and Practice of Aerial Navigation." By Lieut. J. E. Dumbleton. (London: Crosby Lockwood and Son.) 
The position of the Smalls Light, it may be observed, is such that it offers special advantages for the application of the proposed method. A ship rounding the Land's End, bound for the Irish Channel, after passing the Longships Light, has a run of about I30 miles for the Tuskar Light, and towards the end the tidal currents set across the mouth of the Channel with considerable velocity. In such a case observations of the Smalls Light, should it become visible on the starboard bow, would be of considerable service in checking the course laid for the Tuskar.

H. B. G.

\section{Late Keltic Remains from a Mendip Cave.}

$\mathrm{A}^{\mathrm{N}}$ $\mathrm{N}$ important series of Late Keltic objects has been brought to light by members of the Speleological Society of the University of Bristol in the course of investigations in a cave in the Mendips. The cave was first discovered in September, 1919, and the work of exploration, which has been done on most systematic lines, has been carried on throughout the past year. The finds, which were described by Mr. L. S. Palmer at a recent meeting of the Royal Anthropological Institute, included objects of worked bone and stone, bronze hubs and bands of chariot-wheels, bronze bracelets and finger-rings, iron slave shackles, an iron kev, spindle whorls, and similar objects. A considerable amount of pottery was also found which in design and technique was comparable to that found in most Late Keltic settlements. It does not, however, exhibit the characteristic curvilinear motives, the chief decorative feature being in the form of an inverted $\mathrm{C}$. Only three human bones were discovered. There was a large number of bones of domestic and wild animals. A peculiar feature of the discovery is that all these objects were found either on the surface of the floor of the cave or in a thin band of mud which constituted the uppermost layer. There was no evidence of earlier occupation or any trace of Roman occupation. These facts, taken in conjunction with evidence which points to occupation of the cave having taken place in abnormal circum- stances, would suggest that the cavern was used as a temporary refuge.

The discovery is of great importance in connection with the question of the relations which subsisted between this country and the Continent during the Iron age. The character of the finds, and in particular the close affinity exhibited by the pottery to that of Brittany, pointed, in Mr. Palmer's opinion, to the site having been occupied by a tribe of the Brythons who migrated to this country from the north of France. The same people built Glastonbury Lake Village, and are known to have inhabited Wookey Hole, Worlebury Camp, and some hut circles on Brean Down, all of which are within a few miles of this cave. In support of his view Mr. Palmer pointed out that the hill forts in this area all face in a northerly direction, which would suggest that they were the van of a wave of immigration from the south. On the other hand, as Prof. Keith pointed out, the type of skull usually associated with this type of culture in the west of England differs essentially from the Breton skull, and the affinity between the pottery of this area and that of Brittany may well be the result of commerce rather than of immigration. It may be hoped that the further exploration of the site which is to be carried on during the coming year may produce fresh evidence to throw light upon a period concerning which our present knowledge is all too scanty.

\section{Physiology at the British Association.}

$\mathrm{O}$ Tuesday, August 24, the Section of Physiology held a joint meeting with the Sub-Section of Psychology. At this joint sitting Dr. Rivers opened a discussion on the desirability of establishing a separate Section of Psychology. The address of the chairman of the Sub-Section (Dr. C. S. Myers) was on almost the same subject. Dr. Rivers gave an outline of the history of psychology in relation to the British Association, and showed that there had been a great increase in the number of papers on psychological subjects contributed to the Association. He pointed out that psychology had developed methods and problems of its own. At the end of the discussion Dr. Rivers moved a resolution: "That this meeting of the Section approves of the constitution of a separate Section of Psychology." This resolution was passed nem. con., and it was referred to the committee of the Section.

At the same joint meeting Miss M. Smith and Dr. W. McDougall read a paper on "The Effect of Drugs on Fatigue." Fatigue was induced by sitting up all night for three successive nights, and the effect was studied by means of dotting circles on a moving tape and by memory tests with related words. The first effect of fatigue was to increase the efficiency, but after the first few days the efficiency showed a marked decline and remained below the normal for from sixteen to nineteen days. This showed that the effect of the loss of sleep extended for a considerable period after the loss of sleep had occurred. The NO. 2669 , VOL. IO6] drugs were given disguised so that they could not be recognised. Most of the experiments were with alcohol or opium. The action of alcohol was to decrease the efficiency except during the period of recovery, when a stage occurred in which alcohol caused the efficiency to approach the normal nonfatigued value. Opium caused an increase in efficiency which was more marked in the recovery stage. When the dotting and memory tests were carried out together alcohol caused them to vary together, and the subjective effect was not unpleasant, but opium caused one process to improve at the expense of the other, and the subjective effect was distinctly unpleasant.

On Friday, August 27, the Section of Physiology met the Section of Botany to discuss "Biochemistry and Systematic Relationship." An account of this discussion appears in the article upon the proceedings of the Section of Botany (p. 550).

Several of the meetings of the Section were held in the new buildings for the department of physiology, when the members of the Section had the privilege of inspecting the excellent accommodation for the department. At one of these meetings Prof. Haycraft demonstrated a new pulse recorder, which consists of a mirror resting on the artery, the records being made by photographing the movement of a spot of light reflected from the mirror.

Dr. 'T. Lewis read a paper on "The Relation of Physiology to Medicine." This was largely a plea 